\title{
ADUBAÇÃO POTÁSSICA DO ALGODOEIRO: ÉPOCA, MODO DE APLICAÇÃO E TIPO DE FERTILIZANTE $\left.{ }^{(}\right)$
}

\author{
NELSON MACHADO DA SILVA $\left({ }^{2}\right)$, MILTON GERALDO FUZATTO $\left({ }^{2}\right)$, \\ EDERALDO JOSE CHIAVEGATO $\left({ }^{2}\right)$, CARLOS ANTONIO MENEZES FERRAZ $\left({ }^{3}\right)$, \\ e RUTER HIROCE( ${ }^{4}$ )
}

\begin{abstract}
RESUMO
Os efeitos de diferentes tipos de adubos potássicos, doses, Épocas e modo de aplicação foram avaliados em oito experimentos de campo, conduzidos com algodoeiro no período 1962-79, em diversos municípios paulistas. Em dois ensaios, cloreto e sulfato de potássio, nas doses de 40,80 e $120 \mathrm{~kg}$ de $\mathrm{K}_{2} \mathrm{O}$ por hectare, foram aplicados no sulco de plantio, como é usual na lavoura, ou em sulcos efetuados cerca de trinta dias antes da semeação. Nos demais, o cloreto de potássio, na dose de $80 \mathrm{~kg}$ de $\mathrm{K}_{2} \mathrm{O}$ por hectare foi aplicado dos seguintes modos: a) no plantio, na forma usual; b) no desbaste, em cobertura incorporada ou nao; c) no florescimento, em cobertura ou incorporado em sulco lateral; d) parte no plantio e parte em cobertura no desbaste, ou incorporado no florescimento. Os dados de produção foram analisados tanto individualmente como em conjunto, tendo sido reunidos em grupos por similaridade na natureza dos tratamentos. Um dos ensaios foi mantido em caráter permanente para estudo do acúmulo de adubaçoes anuais. Em tal caso, sto điscutidos, também, os teores de $\mathrm{K}, \mathrm{Ca}$ e Mg nas folhas. Em geral, o algodoeiro reagiu favoravelmente à adubaçđo potássica. Não se observaram diferenças entre as adubaçoes com cloreto ou com sulfato. $\mathrm{O}$ uso de potássio em sulcos antes do plantio mostrou-se ineficaz, enquanto a aplicação em cobertura, juntamente com nitrogênio, seguida đe cultivação, logo após o desbaste, parece uma boa altemativa para a adubação tradicional. Com o acúmulo anual de potássio no solo, diminuiu a reação das plantas a doses e a modo de aplicação, denotando efeito residual. Quanto à análise foliar, o pecíolo e o limbo mostraram-se sensíveis à diagnose da nutriçāo potássica, ao mesmo tempo que se consta-
\end{abstract}

( $\left.{ }^{1}\right)$ Recebido para publicação em 28 de maio de 1984.

(2) Seção de Algodđo, Instituto Agronómico (IAC), Caixa Postal 28, 13100 - Campinas (SP).

(3) Divisão de Estaçסes Experimentais, IAC.

( $\left.{ }^{4}\right)$ Seção de Fertilidade do Solo e Nutrição de Plantas, IAC. 
tou, mais uma vez, antagonismo entre concentraçбes de potássio e de magnésio, em relação à adubação potássica, e antagonismo entre potássio e cálcio em relação à parte da folha analisada.

Termos de indexação: algodoeiro; adubação potássica, cloreto e sulfato, época e modo de aplicação; efeito residual e análise foliar.

\section{INTRODUÇÃO}

Através de vários experimentos de campo, demonstrou-se que, em condiçðes de deficiência potássica, há vantagens em parcelar a adubação com cloreto de potássio, contanto que a quantidade a ser aplicada em cobertura, na época do desbaste, seja incorporada ao solo na operação de "chegamento de terra" ao colo das plantas (SABINO et alii, 1984; SILVA et alii, 1984). Outros modos e épocas de adubação com potássio, em parte já relatados (NEVES \& FREIRE, 1957) foram testados em ensaios conduzidos com o algodoeiro antes do referido estudo. Com o objetivo de completar essas informaçסes, no presente trabalho são apresentados e discutidos resultados de oito experimentos de campo.

\section{MATERIAL E MÉTODOS}

Em 1962/63 e 1963/64, no município de Campinas (SP), foram conduzidos dois ensaios de campo com o objetivo de estudar os efeitos de doses de potássio, tipos de adubos potássicos e épocas de aplicação sobre a produção do algodoeiro. Utilizou-se esquema de parcelas subdivididas, com distribuição em blocos ao acaso, com quatro repetiçбes. Épocas e tipos de adubos ocuparam as parcelas, enquanto nas subparcelas foram estudadas as doses de potássio, perfazendo um total de treze tratamentos. Cloreto e sulfato de potássio foram aplicados nos sulcos de plantio ou em sulcos efetuados cerca de 30 dias antes dessa operação, fornecendo 40,80 e120kg de $\mathrm{K}_{2} \mathrm{O}$ por hectare; plantou-se, por parcela, uma testemunha sem potássio.

Nos municípios paulistas de Santo Antônio de Posse e Conchal em $1972 / 73$ e 1973/74, foram efetuados mais dois ensaios visando avaliar os efeitos de dose, época e modo de aplicação de potássio. Em esquema de quadrado latino ( $7 \times 7$ ) estudaram-se os seguintes tratamentos: testemunha, sem potássio; doses de 40 e80kg de $\mathrm{K}_{2} \mathrm{O}$ por hectare, aplicadas no sulco de plantio; dose total $(80 \mathrm{~kg} / \mathrm{ha})$, em cobertura convencional, por ocasião do desbaste; dose total, em sulco lateral à linha das plantas, no início do florescimento; meia dose (40kg/ha) no sulco de plantio, e meia dose em cobertura, no desbaste; finalmente, meia dose no sulco de plantio e meia dose em sulco lateral, no inficio do florescimento. 
No sulco de plantio, os adubos foram aplicados ao lado e abaixo da linha das sementes, como é de praxe (RIGHI et alii, 1965). Na cobertura convencional, o cloreto foi jogado ao solo, em faixas, sob a copa das plantas, misturado ao sulfato de amônio. No florescimento, forneceu-se o potássio em sulco raso ( $\pm 5 \mathrm{~cm}$ de profundidade), distante 10 a $15 \mathrm{~cm}$ do colo das plantas, cobrindo-se o adubo após aplicação.

A partir de 1974/75, instalou-se ensaio em outra propriedade do município de Conchal (SP) com ligeira alteração nos tratamentos. Os três primeiros citados na série anterior não foram modificados, mantendo-se, também, aquele onde se forneceu dose total incorporada, no início do florescimento. Introduziu-se uma aplicação de dose total em cobertura incorporada, no desbaste, eliminando-se os dois últimos. O esquema adotado foi de quadrado latino, com seis tratamentos. Em 1975/76, 1976/77 e 1977/78, avaliou-se o efeito do acúmulo de adubo potássico. Quanto ao modo de aplicação, introduziu-se apenas a cobertura incorporada, no desbaste. Nesse caso, o cloreto de potássio e o sulfato de amônio foram aplicados em cobertura convencional, cobrindo-se totalmente a mistura de adubos pela passagem de cultivador, com enxadas laterais adaptadas para jogar bastante terra nos pés das plantas.

Por fim, em 1978/79, o ensaio foi repetido em nova gleba experimental, na mesma propriedade de Conchal, com uma modificação nos tratamentos. À relação anterior, acrescentou-se uma aplicação de dose total em cobertura convencional, no desbaste. $\mathrm{O}$ esquema foi de quadrado latino, com sete tratamentos.

Sulfato de amônio e superfosfato simples foram usados na adubação básica dos experimentos: utilizaram-se 50 e $60 \mathrm{~kg}$ de $\mathrm{Ne}_{2} \mathrm{O}_{5}$, respectivamente, por hectare, exceto nos dois ensaios de Conchal, onde foram usadas as doses de 30 e $40 \mathrm{~kg} / \mathrm{ha}$.

Em 1962/63 e 1963/64, os ensaios foram semeados com a variedade IAC $\mathrm{RM}_{2}$; de 1972 a 1974, com a IAC 13-1; de 1975 a 1977, com a IAC 16 e, em 1978, com a IAC 17. Em todos os experimentos, os canteiros experimentais constaram de quatro linhas de $5 \mathrm{~m}$ de comprimento, sendo as duas centrais consideradas úteis para a coleta de dados de produção. Foi efetuada análise de variância dos dados tomados individual e conjuntamente, tendo-se estabelecido três grupos em função da natureza dos tratamentos. Os ensaios de 1962/63 e 1963/64 foram analisados em conjunto, assim como os de 1972/73 e 1973/74, por apresentarem entre si tratamentos comuns. $O$ terceiro grupo foi formado pelos ensaios de 1974/75 e 1978/79, com apenas um tratamento não comum; nesse caso, para a análise conjunta, adotou-se esquema proposto por PIMENTEL GOMES (1970).

O ensaio estabelecido em 1974/75 foi mantido em caráter perma- 
nente por 4 anos. Estudou-se o efeito do acúmulo de adubação potássica nos anos subseqüentes, exceção feita a 1975/76, ano em que um ataque intenso de pragas prejudicou a produção.

\section{RESULTADOS E DISCUSSÃO}

No quadro 1 , são apresentados resultados de análise química de amostras de solos dos experimentos. Não foi possível recuperar informaçסes do ensaio conduzido em Campinas, relativo a 1963/64. Também não constam resultados de 1976/77 e 1977/78, do município de Conchal, uma vez que o ensaio de 1974/75 foi mantido na mesma gleba, em caráter permanente.

\begin{tabular}{|c|c|c|c|c|c|c|c|c|c|c|}
\hline \multirow{2}{*}{ Local } & \multirow{2}{*}{$\begin{array}{c}\text { Ano } \\
\text { agrícola }\end{array}$} & \multicolumn{8}{|c|}{ Análise quimica } & \multirow{2}{*}{$\begin{array}{c}\mathrm{Ca}+\mathrm{Mg} \\
\mathbf{K} \\
\text { (Calculado) }\end{array}$} \\
\hline & & MO & $\mathrm{pH}$ & $\mathrm{Al}^{3+}$ & $\mathrm{Ca}^{2+}$ & $\mathrm{Mg}^{2+}$ & $\mathrm{K}^{+}$ & $\mathbf{P}$ & $\mathrm{PO}_{4}^{3-}$ & \\
\hline & \multicolumn{3}{|c|}{$\%$} & \multicolumn{4}{|c|}{ - meq/100ml $\longrightarrow$} & $\mathrm{mg} / \mathrm{ml}$ & e.mg/100g & \\
\hline Campinas & $62 / 63$ & 3,6 & 5,5 & n.d. & 5,0 & n.d. & 0,18 & - & $0,53^{(1)}$ & $>28$ \\
\hline $\begin{array}{l}\text { Santo Antônio } \\
\text { de Posse }\end{array}$ & $72 / 73$ & 2,7 & 6,3 & 0,0 & $\left.6,6{ }^{(3)}\right)$ & - & 0,18 & - & $0,05^{(2)}$ & 37 \\
\hline Conchat-1 & $73 / 74$ & 2,1 & 6,1 & 0,0 & $3,7^{(3)}$ & - & 0,11 & - & $0,09\left(^{2}\right)$ & 34 \\
\hline Conchat-2 & $74 / 75$ & 3,0 & 5,7 & 0,1 & 1,7 & 0,5 & 0,08 & ${ }_{4}^{\left({ }^{2}\right)}$ & - & 28 \\
\hline Conchal-3 & $-78 / 79$ & 2,7 & 5,4 & 0,4 & 1,7 & 0,6 & 0,07 & $2^{(2)}$ & - & 33 \\
\hline
\end{tabular}

( $\left.{ }^{1}\right)$ Fósforo extraído por solução de ácido oxálico e oxalato de potássio $1 \mathrm{~N}$. $\left({ }^{2}\right)$ Fósforo extraido por ácido sulfürico $0,05 \mathrm{~N}$.

(3) Soma de $\mathrm{Ca}^{2+}+\mathrm{Mg}^{2+}$.

Considerando os valores observados de $\mathrm{K}$ e calculados para a relação $(\mathrm{Ca}+\mathrm{Mg}) / \mathrm{K}$, à luz de critério proposto na literatura para indicar a disponibilidade de potássio (FUZATTO et alii, 1970; SILVA, 1971), deduz-se que as glebas em questao apresentavam condiçסes bastante favoráveis para resposta do algodoeiro a potássio e, portanto, próprias para avaliar modo e época de aplicação do nutriente.

Os resultados de produção obtidos em Campinas encontram-se no quadro 2. Observa-se que o efeito da adubação potássica foi maior no segundo ano agrícola (1963/64), justamente quando não foi possível recuperar informaçסes sobre análise de solo. Nesse caso, a dose de $80 \mathrm{~kg}$ de $\mathrm{K}_{2} \mathrm{O}$ por hectare proporcionou aumento médio estatisticamente significativo de $19 \% \mathrm{em}$ relação à testemunha. 
QUADRO 2 - Produção média de algodão em caroço obtida nos ensaios de dose, época de aplicação e tipo de adubos potássicos, em 1962/63 e 1963/64, no municipio de Campinas (SP)

\begin{tabular}{|c|c|c|c|}
\hline \multirow{2}{*}{ Tratamentos } & \multicolumn{3}{|c|}{ Algodão em caroço } \\
\hline & $1962 / 63$ & $1963 / 64$ & Médias \\
\hline Dose & $\longrightarrow$ & $-\mathrm{kg} / 10 \mathrm{~m}$ & 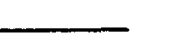 \\
\hline \multicolumn{4}{|l|}{ (kg de $\mathrm{K}_{2} \mathrm{O}$ por hectare) } \\
\hline 0 & $1,058 \mathrm{~b}^{\left({ }^{2}\right)}$ & $2,105 b^{(2)}$ & $1,582 b^{(2)}$ \\
\hline 40 & $1,124 a b$ & $2,297 \mathrm{ab}$ & $1,710 a b$ \\
\hline 80 & $1,195 \mathrm{ab}$ & $2,514 \mathrm{a}$ & $1,855 \mathrm{a}$ \\
\hline 120 & $1,211 \mathrm{a}$ & $2,516 \mathrm{a}$ & $1,863 \mathrm{a}$ \\
\hline \multicolumn{4}{|l|}{ Tipo de adubo $\left({ }^{1}\right)$} \\
\hline $\mathrm{KCl}$ & 1,164 & 2,372 & 1,768 \\
\hline $\mathrm{K}_{2} \mathrm{SO}_{4}$ & 1,130 & 2,345 & 1,738 \\
\hline \multicolumn{4}{|l|}{ Época de aplicação (1) } \\
\hline Antes do plantio & 1,129 & 2,217 & 1,673 \\
\hline No plantio & 1,165 & 2,500 & 1,832 \\
\hline $\mathrm{CV} \%\left({ }^{3}\right)$ & 16,9 & 18,7 & 19,3 \\
\hline "F" Linear - doses de $\mathrm{K}_{2} \mathrm{O}$ & $5,94 *$ & $8,68 * *$ & $13,70 * *$ \\
\hline
\end{tabular}

( $\left.{ }^{1}\right)$ Médias, para doses de $\mathrm{K}_{2} \mathrm{O} .\left(^{2}\right)$ Médias seguidas de mesma letra nåo diferem estatisticamente pelo teste de Duncan, a 5\%. $\left({ }^{3}\right)$ Em nível de subparcela experimental.

No referido ensaio, o comportamento do algodoeiro foi praticamente o mesmo na presença de $\mathrm{KCl}$ ou $\mathrm{K}_{2} \mathrm{SO}_{4}$, confirmando resultados obtidos em trabalhos anteriores (CAMARGO \& CRUZ MARTINS, 1935; NEVES et alii, 1960).

Quanto à época de aplicação, observou-se clara tendência para maior produtividade das plantas quando do uso de potássio no plantio, principalmente em 1963/64, quando essa aplicação superou em cerca de $13 \%$ aquela efetuada antecipadamente. Além de não concorrer para aumento da produtividade das plantas, a aplicação muito antecipada (30 dias antes do plantio) representa uma operação extra a ser efetuada em ocasião inoportuna, pois o solo normalmente está seco. Ademais, com as primeiras chuvas, o solo já adubado propicia a emergência e o crescimento rápidos de ervas daninhas, requerendo nova gradagem e novo sulcamento, como ocorreu nos experimentos.

No quadro 3, encontram-se os resultados de produção obtidos nos 


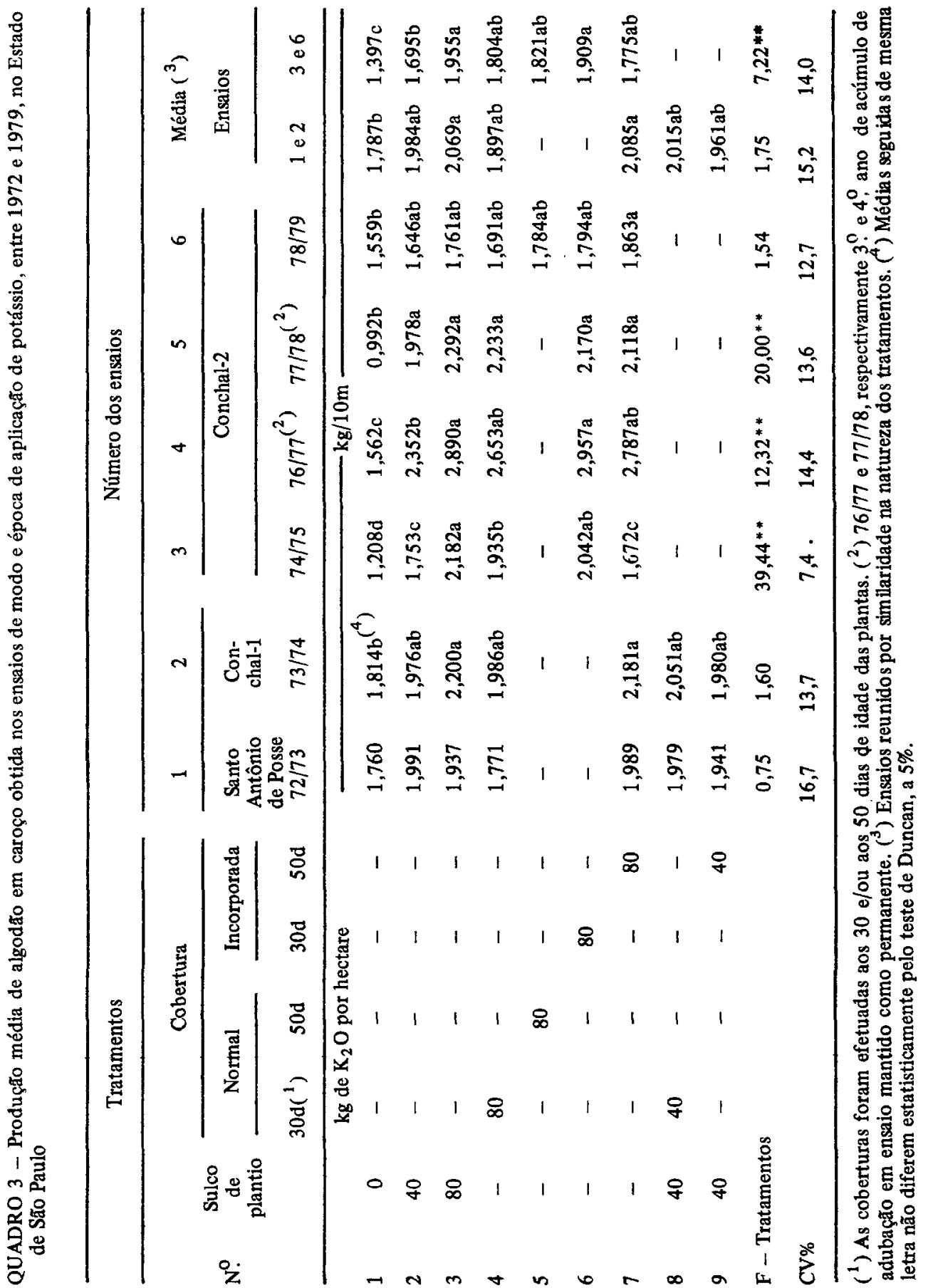


ensaios mais recentes, conduzidos no periodo de 1972/73 a 1978/79 e da análise conjunta de grupos de ensaios reunidos por similaridade na natureza dos tratamentos.

O primeiro grupo foi formado pelos ensaios conduzidos em Santo Antônio de Posse, 1972/73 (no 1) e Conchal, 1973/74 (no 2). A análise conjunta revelou que somente os tratamentos que forneceram dose total no sulco de plantio ou em cobertura incorporada no florescimento, conseguiram superar estatisticamente a testemunha. Os aumentos médios de produção foram, em ordem, $16 \%$ e $17 \%$. No ensaio de Conchal, 1973/74, em gleba mais deficiente em potássio, esses índices foram, respectivamente, 21 e $23 \%$.

A despeito do relativo sucesso da incorporaçao no florescimento, é mister que se diga ter sido constatado corte de raízes das plantas na operação de sulcamento, para introdução do adubo. Embora as plantas tivessem reagido bem a esse pequeno trauma, resta saber se reagiriam da mesma forma, em condiçōes mais drásticas, como de seca excessiva durante o florescimento.

Ainda no quadro 3, pode-se notar, pela análise conjunta do segundo grupó que engloba ensaios ( $\mathrm{n}_{\mathrm{s}} 3$ e 6) conduzidos em solos mais deficientes, que o efeito da adubação potássica foi bem mais acentuado. Na média, o tratamento mais fraco foi a testemunha, destacando-se os tratamentos fornecedores de dose máxima no sulco de plantio e em cobertura incorporada por ocasião do desbaste. Os aumentos médios em relação à produção da testemunha foram, respectivamente, $40 \%$ e $37 \%$. No ano de maior resposta à adubação, $1974 / 75$, tais tratamentos proporcionaram aumentos excepcionais, $81 \%$ e $69 \%$ respectivamente, enquanto o fornecimento de todo o potássio em sulco lateral, no florescimento, nao superou sequer o tratamento de meia dose no plantio: embora essa aplicação mais tardia de potássio tenha apresentado certo destaque, em 1978/79, implica em riscos, tais como: a) em casos de alta deficiência, o nutriente estará sendo aplicado tardiamente; b) a sulcação poderá danificar as raízes em época vital do ciclo das plantas; c) um gasto extra, pois o cloreto estará sendo aplicado dissociado do adubo nitrogenado. Já a incorporação no desbaste é mais segura, pois o sistema radicular das plantinhas ainda é incipiente, é viável, pois o nutriente é colocado à disposição das plantas no início de seu desenvolvimento, e econômica, por aproveitar a cobertura nitrogenada e ser incorporada pela passagem do cultivador, visando chegar terra aos pés das plantas remanescentes à raleação.

O ensaio de Conchal, iniciado em 1974/75, e mantido em caráter permanente durante 4 anos, visando avaliar o efeito do acúmulo de potássio apresentou baixa produtividade em 1975/76, em função de uma série de fatores, razão por que os dados não são apresentados e discutidos.

A produtividade das plantas cultivadas continuamente sem potássio, 
caiu através dos anos. Nota-se, no quadro 3 , que a testemunha produziu, respectivamente, $31 \%$ em $1974 / 75,34 \%$ em $1976 / 77$ e $50 \%$ em $1977 / 78$ a menos que o tratamento com meia dose (n! 2).

As diferenças entre doses, no entanto, diminuíram com o acúmulo da adubação. Com efeito, nota-se no primeiro ano (1974/75), que a quase totalidade dos tratamentos fornecedores de dose máxima de adubo, superou aquele que cedeu meia dose, enquanto no terceiro ano $(1976 / 77)$ tal fato se limitou aos tratamentos nos 3 e 6, e no quarto (1977/78), nao ocorreu diferença estatística significativa entre tratamentos adubados.

Quanto ao modo de aplicar o potássio, os tratamentos que se destacaram no primeiro ano, ou seja, aqueles fornecedores de dose máxima no sulco de plantio (no 3) ou em cobertura incorporada no desbaste (n! 6), não diferiram de outras maneiras de aplicar, no terceiro e quarto ano. Comprova-se, desse modo, o efeito residual da adubação potássica do algodoeiro (NEVES \&FREIRE, 1958) que, no presente caso, se evidenciou inclusive através de diferentes modos de aplicação do nutriente.

No quadro 4 são apresentados os resultados médios obtidos por tratamento de $\mathrm{K}, \mathrm{Ca}$ e $\mathrm{Mg}$ determinados no limbo e pecíolo de folhas colhidas no primeiro e no quarto ano do ensaio permanente de adubação potássica.

No primeiro ano, o efeito de doses de potássio se destacou apenas sobre a concentração de $\mathrm{K}$, concorrendo para aumentá-la tanto no limbo como no pecíolo, conforme já observado (MELLO, 1962; SILVA et alii, 1971).

Quan to ao modo de aplicação, com a incorporação tardia do nutriente feita durante o florescimento, houve tendência para queda na concentração de $\mathbf{K}$ da folha.

No quarto ano de acúmulo da adubação, o efeito de doses foi muito semelhante quanto à concentração do nutriente na folha e se destacou, também, por influenciar negativamente a concentração de $\mathrm{Mg}$, em particular no limbo foliar. Aliás, o conhecido antagonismo entre $\mathrm{K}$ e Mg (HIROCE et alii, 1976; MELLO, 1962) se evidenciou nesse caso, quando numa correlação simples efetuada com os valores individuais dos nutrientes, obteve-se coeficiente com valor altamente significativo $(\mathrm{r}=-0,58 * *)$. No limbo, os teores de potássio foram mais baixos do que no pecíolo, enquanto os teores de cálcio ocorreram antagonicamente em relação aos de potássio nas partes das folhas.

Ainda no quadro 4, nota-se que os teores de potássio revelados pela análise foliar estiveram associados às produçoes correspondentes, em função dos altos valores dos coeficientes de correlação simples obtidos com os resultados individuais. Isso sugere que, em condiçôes de alta deficiência potássica, tanto o limbo como o pecfolo mostram-se como partes da planta sensiveis à 


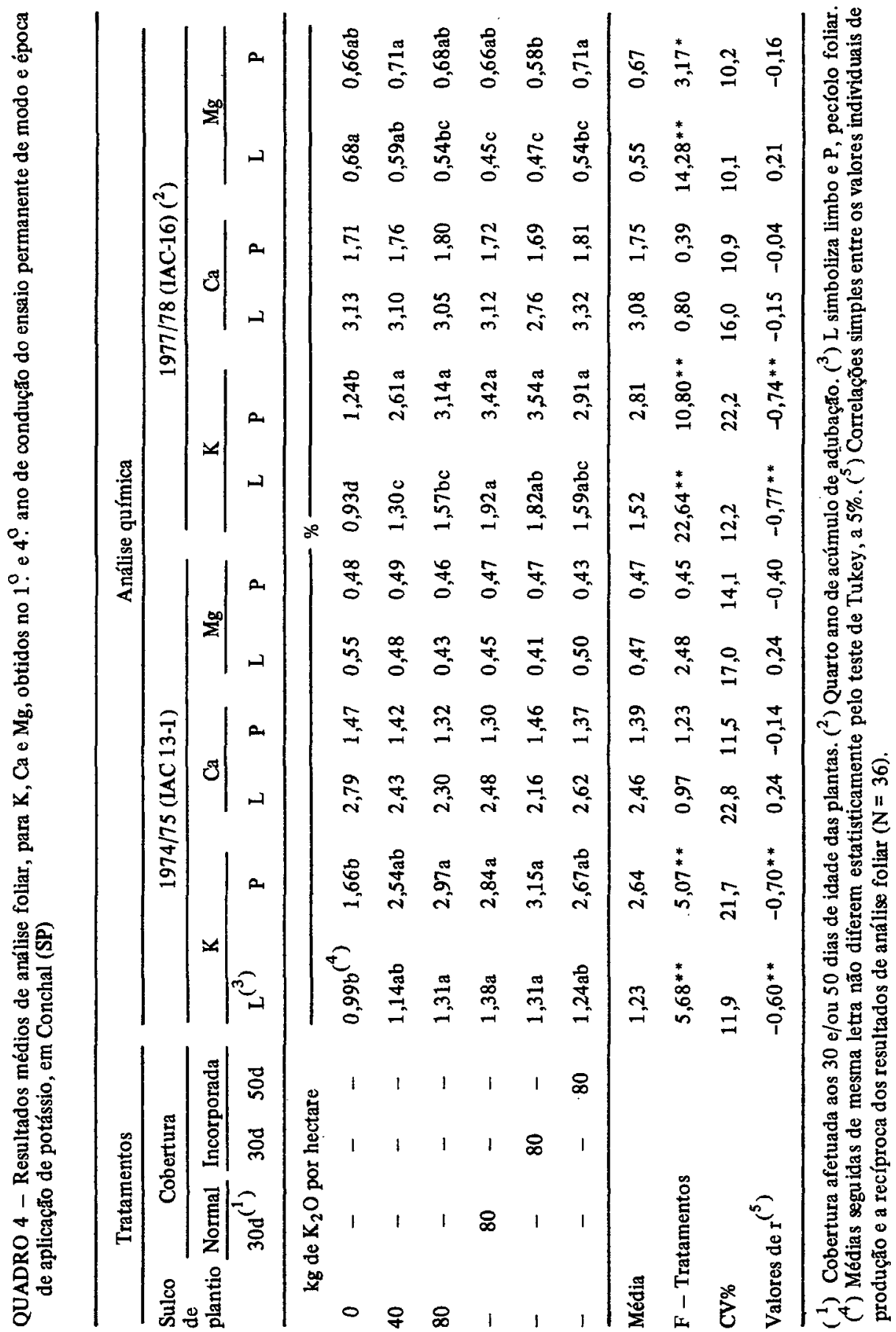


diagnose da nutrição do algodoeiro, a despeito de a concentração no pecíolo ser bem mais elevada.

\section{CONCLUSÕES}

Alguns aspectos devem ser ressaltados da discussão dos resultados aqui expostos e obtidos em ensaios em que o algodoeiro reagiu muito bem à adubação potássica. Nota-se que:

a) o algodoeiro teve comportamento semelhante quando adubado com cloreto ou com sulfato de potássio;

b) o emprego de adubo potássico em sulcos efetuados antes do plantio mostrou-se ineficaz;

c) a aplicação de cloreto misturado ao adubo nitrogenado, por ocasião do desbaste, com posterior incorporação pela passagem do cultivador, mostrou-se alternativa viável para a adubação tradicional, no sulco de plantio;

d) com o acúmulo de potássio nas adubações anuais consecutivas, as diferenças entre doses e entre modo de aplicação tenderam a diminuir, revelando efeito residual na cultura algodoeira;

e) o limbo e o pecíolo das folhas do algodoeiro mostraram ser partes indicadas à diagnose da nutrição potássica;

f) mais uma vez, constatou-se o conhecido antagonismo entre a absorção de $\mathrm{K}$ e Mg, através da análise do limbo foliar;

g) no limbo o teor de $\mathrm{K}$ foi mais baixo que o de $\mathrm{Ca}$, ocorrendo a ordem inversa no pecíolo.

\section{SUMMARY}

\section{POTASSIC FERTILIZATION IN COTTON: TIME AND MODE OF APPLICATION, AND KIND OF FERTILIZER}

Effect of time and mode of applications, as well as of dose and kind (chiloride and sulfate) of potassic fertilizer were observed in eight cotton field experiments, during the period 1962/1979, at three locations of the State of Sao Paulo, Brazil. In two experiments, potassium fertilizers, at 40,80 and $120 \mathrm{~kg} / \mathrm{ha}$ of $\mathrm{K}_{2} \mathrm{O}$, were applied in the furrows at planting time, or added to the soil in furrows 30 days before planting. In another experiments, potassium chloride at $80 \mathrm{~kg} / \mathrm{ha}$ de $\mathrm{K}_{2} \mathrm{O}$, was applied in several manners; a) in the furrows at the planting time; b) just after thinning by spreading with $N$ over the rows and covering or not with soil by subsequent cultivation; c) at flowering, by spreading over the rows or in furrows with incorporation; d) partial application, being part used at planting, and part spread over the rows, after thinning, or in furrows, at flowering. The statistical analysis of cotton yield were done individually, by experiment, or in groups according to the similarity in the 


\begin{abstract}
treatments. One of the experiments was kept by four successive years in the same field, in order to check the cumulative effect of fertilization. In such case, it was also considered the contents of $\mathrm{K}, \mathrm{Ca}$ and $\mathrm{Mg}$ in the leaves. In general, cotton reacted positively to potassium fertilization. However, there was no appreciable difference between potassium chloride and sulfate. Fertilizer application in furrows before planting, showed to be inefficient, while the use of $\mathrm{K}$ with $\mathrm{N}$ in side-dressing, followed by cultivation, just after thinning, seems to be a good alternative. Due to potassium accumulation in successives annual fertilizations, the reaction of cotton to doses decreased regardless of the mode of nutrient application. About leaf analyses results, either petioles or leaf blades showed to be pieces of plant very sensitive to diagnosis of potassium nutrition. There was a negative correlation between $\mathrm{K}$ and $\mathrm{Mg}$ content in leaf blades, and between $\mathrm{K}$ and $\mathrm{Ca}$ content with regard to leaf part analysed.
\end{abstract}

Index terms: cotton, potassium fertilization, chloride and sulfate, time and way of application, residual effect and foliar analyse.

\title{
AGRADECIMENTO
}

Os autores agradecem ao Dr. R. Forster, na oportunidade Chefe do Centro Experimental de Campinas, e aos Srs. L. Lolli, de Santo Antônio de Posse, e H. Plonk e G. Fadel, de Conchal, a colaboração prestada.

\section{REFERÊNCIAS BIBLIOGRÁFICAS}

CAMARGO, T. \& CRUZ MARTINS, R. A adubação do algodoeiro em terras roxas cansadas. In: CONFERENCIA NACIONAL ALGODOEIRA, São Paulo, 1935. Anais. p.31-40.

FUZATTO, M.G.; VENTURINI, W.R. \& CAVALERI, P.A. Estudo técnico-econômico do algodoeiro no Estado de São Paulo. Campinas, Instituto Agronômico, 1970. 15p. (Projeto BNDE/ANDA/CIA - Publicação,1)

HIROCE, R.; SILVA, N.M.; NAGAI, V., BATAGLIA, O.C. \& GALLO, J.R. Diagnose da nutrição nitrogenada e potássica do algodoeiro (Gossypium hirsutum "IAC 13-1") pela análise química foliar. Ciência e Cultura, São Paulo, 28(1): 51-56, 1976.

MELLO, F.A.P. A relação $\mathrm{K} / \mathrm{Mg}$ em folhas de algodoeiro cultivado em condições de campo. Anais da Escola Superior de Agricultura "Luiz de Queiroz", Piracicaba, 19:67-74, 1962.

NEVES, O.S.; CAVALERI, P.A.; ABRAMIDES, E. \& FREIRE, E.S. Adubação do algodoeiro. X-Ensaios com diversos adubos potássicos. Bragantia, Campinas, 19(12): 183-200, 1960.

\& FREIRE, E.S. Adubação do algodoeiro. IV-Ensaios sobre época de aplicação de azoto e potássio. Bragantia, Campinas, 16:269-296, 1957.

\& Efeito residual dos adubos potássicos. Bragantia, Campinas, 17: XIX-XXX, 1958. (Nota, 5) 
PIMENTEL GOMES, F. Curso de Estatística Experimental. 4.ed. Piracicaba, Escola Superior de Agricultura "Luiz de Queiroz", 1970. 430p.

RIGHI, N.R.; FERRAZ, C.A.M. \& CORREA, D.M. Cultura. In: NEVES, O. da S. et alii, Cultura e adubação do algodoeiro. São Paulo, Instituto Brasileiro de Potassa, 1965. cap. 7, p.255-317.

SABINO, N.P.; SILVA, N.M.; SABINO, J.C. \& KONDO, J.I. Efeito do parcelamento da adubação potássica em características agronômicas e propriedades tecnológicas da fibra do algodoeiro. Bragantia, Campinas, 43, (1):221-228, 1984.

SILVA, N.M. Importância da seleção de glebas para estudos de adubação do algodoeiro. Campinas, Instituto Agronômico, 1971. 11p. (Projeto BNDE/ANDA/CIA - Publicação, 8)

; CARVAlHO, L.H.; CIA, E. \& CHIAVEGATO, E.J. Estudo do parcelamento da adubação potássica do algodoeiro. Bragantia, Campinas, 43, (1):111-124, 1984.

; HIROCE, R. \& FUZATTO, M.G. Efeito da adubação sobre o desenvolvimento e a produção de duas variedades de algodão, em latosol roxo intensamente cultivado. Campinas, Instituto Agronômico, 1971. 8p. (Projeto BNDE/ANDA/CIA - Publicação, 5) 